\title{
Slikanice v prvem starostnem obdobju
}

\author{
Janja Batič \\ Univerza v Mariboru \\ janja.batic@um.si \\ Dragica Haramija \\ Univerza v Mariboru \\ dragica.haramija@um.si
}

V prispevku se osredinjamo na branje slikanic otrokom v prvem starostnem obdobju. Razvoj pismenosti je vseživljenjski proces, ki ga odrasli prenašamo na otroke in smo zanj odgovorni. Od otrokovega prvega leta starosti dalje gre za razvijanje družinskega branja, ko otroku berejo njegovi bližnji odrasli (neprofesionalni posredniki branja), z vstopom v vrtec pa se otrok sreča z usmerjenimi izobraževalnimi dejavnostmi, povezanimi s pismenostjo. Slikanice za prvo starostno obdobje so predstavljene glede na oblikovne posebnosti: uporabljeni materiali, velikosti slikanic (za otrokovo rokovanje), oblike slikanic (knjige z zavihki, knjige z vrtljivimi elementi, »pop-up« knjige ...), slikanice z zvočnimi elementi, z dodanimi lutkami ipd. Vsebinske omejitve leposlovnih in informativnih slikanic so predstavljene glede na otrokov celostni razvoj.

Ključne besede: pismenost, slikanice, informativne slikanice, leposlovne slikanice, prvo starostno obdobje.

\section{Uvod}

Razvijanje bralne pismenosti, ki je vseživljenjski proces, se začne kmalu po otrokovem rojstvu s poslušanjem in z opazovanjem (tudi) raznolikega slikaniškega gradiva. Nujni pogoji za otrokov bralni razvoj so dostopna primerna bralna gradiva, ki jih ima otrok doma, obisk knjižnice, odrasli, ki otroku bere, se z njim o prebranem pogovarja in je otroku tudi bralni zgled, torej da ga otrok vidi, da bere (Krolak 2005, 4). Otrok razvija predbralne veščine in zavedanje o tisku, to so smer branja (od leve proti desni), listanje knjige, orientacija v bralnem gradivu, povezovanje slikovnega in besednega dela v slikanici (interakcija) v celostno multimodalno branje besedil; za vse to pa potrebuje seveda odraslega (neprofesionalnega in profesionalnega) posrednika. Pismenost je pomembna zato, ker omogoča posamezniku, da se v družbi udejstvuje, saj brez razumevanja prebranega v informacijski dobi ni mogoče funkcionirati. Branje ni pomembno zgolj za branje in poslušanje leposlovnih besedil, pač pa pismenost pomeni razumevanje vseh pisnih in govorjenih 
besedil.' Zato je zelo pomembno, da otroke izpostavljamo bralnemu gradivu vse od rojstva, hkrati pa menimo, da so slikanice $v$ tem obdobju najprimernejša oblika knjižnega gradiva. V prispevku se naslanjamo na Gradnike bralne pismenosti (gradivo je nastalo v okviru projekta OBJEM, zadnje spremembe I. 2018), ki veljajo za vsa področja dejavnosti predšolskega (in tudi poznejšega) izobraževanja. Posebej se posvečamo tretjemu gradniku, to je razumevanju koncepta bralnega gradiva, čeprav so seveda upoštevani tudi drugi gradniki bralne pismenosti (govor, motiviranost za branje, glasovno zavedanje, besedišče in razumevanje besedil, odziv na besedilo, kritično branje oz. bistvo prebranega besedila), izjema je 6 . gradnik (tekoče branje), ki ga v prvem starostnem obdobju v vrtcu ne moremo razvijati.

\section{Opredelitev slikanice}

Slikanica je posebna oblika knjige, ki združuje najmanj dva koda sporočanja, to sta jezikovni (besedilo) in likovni (ilustracije) kod, pri čemer je besedilni del navadno manj obsežen od slikovnega in (načeloma) ne presega 1.800 besed. Slikanice imajo tri osnovne sestavine, in sicer besedilo, ilustracije ter odnos med njima, ki ga imenujemo interakcija (Haramija in Batič 2013, 35).

Glede na funkcijske zvrsti jezika so besedila v otroških slikanicah pisana v umetnostnem (leposlovje) ali strokovnem jeziku (informativne slikanice) ali pa združujejo lastnosti obeh (leposlovno-informativne slikanice). Leposlovna besedila so po nastanku ljudska ali avtorska, glede na zvrstno opredelitev pa sodijo v poezijo ali prozo. Informativna besedila za predšolske otroke, izdana v slikaniški obliki, vsebinsko posegajo na vsa področja dejavnosti, ki jih predšolsko izobraževanje razvija (gibanje, jezik, umetnost, družba, narava, matematika). $V$ leposlovnih slikanicah za predšolske otroke so objavljene raznolike teme, med njimi najpogosteje vprašanja odnosov (otrok - odrasli, otrok - sorojenci, otrok - prijatelji) in sprejemanja različnosti, vključujočih odnosov; vprašanja okolja (kjer se kot zelo uporabna kaže ekosistemska delitev: npr. živali v gozdu, mlaka) in bivanjska vprašanja (predvsem razumevanje samega sebe). Ilustracije v slikanici lahko razdelimo na ilustracije, ki so del parabesedila (naslovnica, vezni listi in notranja naslovnica) ter notranje ilustracije (med seboj se ločijo po velikosti). Ilustracije v slikanicah se med seboj razlikujejo po likovnih tehnikah in materialih, ki jih izbirajo ilustratorji pri oblikovanju ilustracij. Ilustratorji vsebino podajajo tako $z$ načinom upodobitve (črta, barva, zorni kot, fokus ...) kot tudi z izbiro motivov, ki jih upodabljajo

${ }^{1}$ Zato pomemben premik pomeni Priporočilo sveta o ključnih kompetencah za vseživljenjsko učenje (2018), ki na prvo mesto med osmimi ključnimi kompetencami uvršča pismenost. 
(prikaz literarnih likov in prostora, medsebojni odnosi med literarnimi liki, geste, simboli ...). Ilustratorji velikokrat posežejo na področje besedilnega koda sporočanja, in sicer tako, da ilustracijo dopolnijo $z$ intraikoničnim besedilom (napisi v ilustraciji, ponovljeni deli besedila, avtorski zapisi ilustratorja ...).

Besedilo in ilustracije se med seboj povezujejo oblikovno in vsebinsko. Z oblikovnega vidika spremljamo umestitev ilustracij in besedila (npr. besedilo, vstavljeno v barvno enovite dele ilustracije); z vsebinskega vidika pa raziskujemo pomen, ki ga soustvarjajo besedilo in ilustracije. Nikolajeva (2003) govori o interakciji in izpostavi naslednje tri glavne kategorije: simetrična (informacije v ilustraciji in besedilu se ponovijo), komplementarna (informacije se dopolnjujejo) in stopnjevalna (slike presegajo besedilo ali obratno) interakcija.

Branje slikanic otrokom pomeni več kot le branje besedila in pasivno opazovanje ilustracij. »Branje« ilustracij pomeni njihovo natančno opazovanje, opisovanje, analiziranje in interpretiranje. Gre za proces, ki ga vodi odrasel posrednik branja (npr. vzgojitelj, starši). Cilj je otroke čimbolj usmeriti v pozorno opazovanje in iskanje informacij, ki pomenita sestavni del pri razbiranju pomena v slikanici. Posebno pozornost pri branju otrokom morajo odrasli posredniki branja nameniti tudi samemu tisku. Odrasli namreč otroke le redko usmerjajo v posebnosti tiska, npr. velikost in obliko črk, besedilo, zapisano v oblačku, intraikonično besedilo (Piasta idr. 2012). Hkrati pa raziskave kažejo na povezanost med zgodnjim spoznavanjem s tiskom in uspešnejšim razvijanjem bralnih veščin (Marjanovič Umek 2007; Piasta idr. 2012).

\section{Značilnosti slikanic v prvem starostnem obdobju}

J. Dwyer in S. B. Neuman (2008, 490-494) obdobje od rojstva do četrtega leta razdelita $v$ tri skupine, in sicer govorita o knjigah za: dojenčke (od rojstva do 12 mesecev), malčke (od 12 mesecev do treh let) in predšolske otroke (od treh do štirih let). $V$ nadaljevanju se bomo osredotočili (predvsem) na prvi dve skupini. Razumevanje besedil je $v$ tem obdobju močno odvisno od otrokovega govornega razvoja, njegovega obvladovanja besedišča, nenazadnje od njegovega ugodnega ali neugodnega jezikovnega položaja v družini (otrokov materni/prvi jezik; jezik izobraževanja; jezik okolja). L. Marjanovič Umek poudarja npr., da je za otrokov govorni razvoj pomembno malčkovo metajezikovno zavedanje, predvsem pa so za otrokove jezikovne kompetence (Marjanovič Umek 2007, 37) "pomembne že kakovostne socialne interakcije med malčki in starši, starševski govor (govor, ki ga starši namenijo malčkom) in starševski slog«.

Otrokov kognitivni razvoj pri branju in pisanju pogojuje njegovo zmožnost 
vidnega razločevanja (pri čemer mislimo na razločevanje črk in njihovo povezovanje $v$ besede), razumevanje jezikovnih struktur (na vseh jezikovnih ravninah) in besedni zaklad. S. Pečjak $(1995,11)$ navaja, da "pojem besedni zaklad pri branju označuje število besed v pisni obliki, ki jih posameznik prepozna. Bralno besedišče predstavlja pasivno (receptivno) besedišče, ki se razlikuje od besedišča v govoru in pri pisanju, ki je aktivno besedišče. [...] Vsako leto naj bi učenci pridobili od 2700 do 3000 novih besed. [...] Razmerje med aktivnim in pasivnim besediščem je v povprečju 1:3- do 4-kratno, kar pomeni, da je besedišče pri branju 3- do 4-krat večje kot besedišče $v$ govoru ali pri pisanju. Enako je z besednjakom pri dojenčkih in malčkih, pri čemer L. Marjanovič Umek navaja raziskave, ki so opravljene s pomočjo standardiziranega seznama besed (Bates in Goodman 2001), in sicer, da (Marjanovič Umek 2007, 38): »dojenčki, stari 12 mesecev, uporabljajo od o do 52 besed; malčki, stari 16 mesecev, od o do 347 besed; malčki stari 30 mesecev, od 208 do 675 besed. ${ }^{2}$

Pri dojenčkih in malčkih je treba ob besednjaku upoštevati tudi primerno temo, motive, skladnjo, stilistične elemente, vsebino, ki dojenčka ali malčka zanima in jo razume, nenazadnje primerno obliko slikanice. Slednja mora biti premišljeno izbrana tako $z$ vidika uporabljenih materialov kakor tudi velikosti: predvsem so uporabni manjši formati in mehkejši materiali.

J. Dwyer in S. B. Neuman (2008) poudarjata, da morajo biti knjige, ki so namenjene otrokom do enega leta, dovolj debele, da jih lahko otrok prime $v$ roke in obrača strani: strani iz tršega kartona ali mehke plastične mase lahko pripomorejo k razvoju spretnosti, potrebnih za listanje "pravih« knjig. Avtorici pravita tudi, da naj bi otrokom, ki so mlajši od štirih mesecev, ponudili slikanice $z$ močno kontrastnimi barvami, kot sta črna in bela ali rdeča in zelena, ter z večjimi vzorci (Dwyer in Neuman 2008). $Z$ likovnega vidika dojenčkom ponujamo preproste velike slike živali in poznanih vsebin, kot so družinsko življenje, obrazi, hrana, oblačila. Podobe naj bi bile večje in naj bi se nahajale na kontrastnem ozadju (Dwyer in Neuman 2008). V drugem obdobju (od enega do treh let) so otroci motorično spretnejši in obvladujejo knjige standardne velikosti, kljub temu pa morajo biti knjige še vedno iz močnejših in trajnejših materialov.

\footnotetext{
${ }^{2}$ Analiza težavnostnih stopenj besedil je lahko dober pripomoček za določanje (seveda povprečne) zmožnosti otrokovega razumevanja izbranega besedila, npr: A Parent's Guide to Guided Reading (https://www.scholastic.com/parents/books-and-reading/readingresources/book-selection-tips/parents-guide-to-guided-reading.html) ali na spletni strani založbe Harper Collins (https://www.icanread.com/levels/) ali na spletni strani The Lexile Analyser; https://lexile.com/educators/tools-to-support-reading-at-school/tools-to-determine-a -books-complexity/the-lexile-analyzer/).
} 
$V$ drugem letu starosti branje slikanic pomaga otrokom razumeti, da so slike v knjigi simboli oz. predstavitve objektov (Snow in Ninio 1986 po Dwyer in Neuman 2008). Prav zato je zelo pomembna stopnja podobnosti med sliko in predmetom (Ganea, Bloom Pickard in DeLoache 2008). Otroci v drugem letu starosti spoznajo novo besedo ob sliki v slikanici in jo prenesejo na realni predmet ter obratno, ko spoznajo novo besedo za realni predmet, jo prepoznajo tudi v realistični upodobitvi v slikanici. Hkrati pa tega niso sposobni narediti, če je namesto realistične upodobitve prisotna karikaturna. Slednje je pomembno predvsem pri oblikovanju informativnih slikanic. Z likovnega vidika $v$ drugem razvojnem obdobju za otroke izbiramo slikanice $s$ poznanimi podobami, npr. družina, obrazi, hrana, igrače, tematske vsebine, podobe pa naj bi bile na vsaki strani slikanice (Dwyer in Neuman 2008). Okoli tretjega leta otrokove starosti postane pomembna vsebina, otroci se že osredotočijo na zgodbo, in sicer prerastejo stopnjo preprostega opazovanja slik in poimenovanja (Dwyer in Neuman 2008).

$\checkmark$ predbralnem obdobju otroci razbirajo pomene iz ilustracij v slikanicah. Ob branju slikanic in slikanic brez besedila se naučijo rokovati s knjigo, komentirajo ilustracije, sledijo pripovedi in uporabljajo različne strategije. Te so: iskanje (iskanje podatkov iz besedila, slike, lastnih izkušenj), navzkrižno preverjanje (preverjanje, ali je neka nova informacija skladna s tem, kar že poznajo), popravljanje samega sebe (na podlagi novih informacij otroci spremenijo pomen tega, kar so že prebrali oz. slišali) in ponovno branje (Lysaker in Hopper 2015).

\section{Oblikovne posebnosti slikanic za najmlajše otroke}

Slikanice, ki so namenjene otrokom v prvem starostnem obdobju, se od drugih knjig bistveno razlikujejo po materialu. Izdelane so iz blaga, umetne mase ali največkrat iz kartona. Blago in umetne mase, torej mehkejši materiali, rokovanje s knjigo omogočajo že dojenčkom. Pojavljajo pa se tudi kartonke, ki imajo mehkejše platice (slika 1). Slikanice, ki so namenjene otrokom v prvem starostnem obdobju, se razlikujejo tudi po velikosti (slika 2) in obliki (slika 3).

Med slikanicami, ki so namenjene otrokom prvega starostnega obdobja, lahko najdemo takšne nepravilnih oblik, ki posnemajo upodobljene like (prim, avtobus, polh). Nekatere slikanice za malčke izhajajo kot zbirke, npr. dela Lorelle Rizzatti (1993); izdane so lahko tudi v kompletu, npr. škatla Moja knjižnica: prve besede, ki vsebuje osem slikanic (Hrana 2018), gre za prevode kompleta Building Blocks Learning Library: First Words. Nekaj je tudi slikanic, ki imajo dodane ročne lutke ali pa različne odprtine, npr. delo Erica Carla Zelo lačna gosenica (1997). 
Slika 1

Primer slikanice $z$ mehkimi listi (Otrokove prve besede 2011)
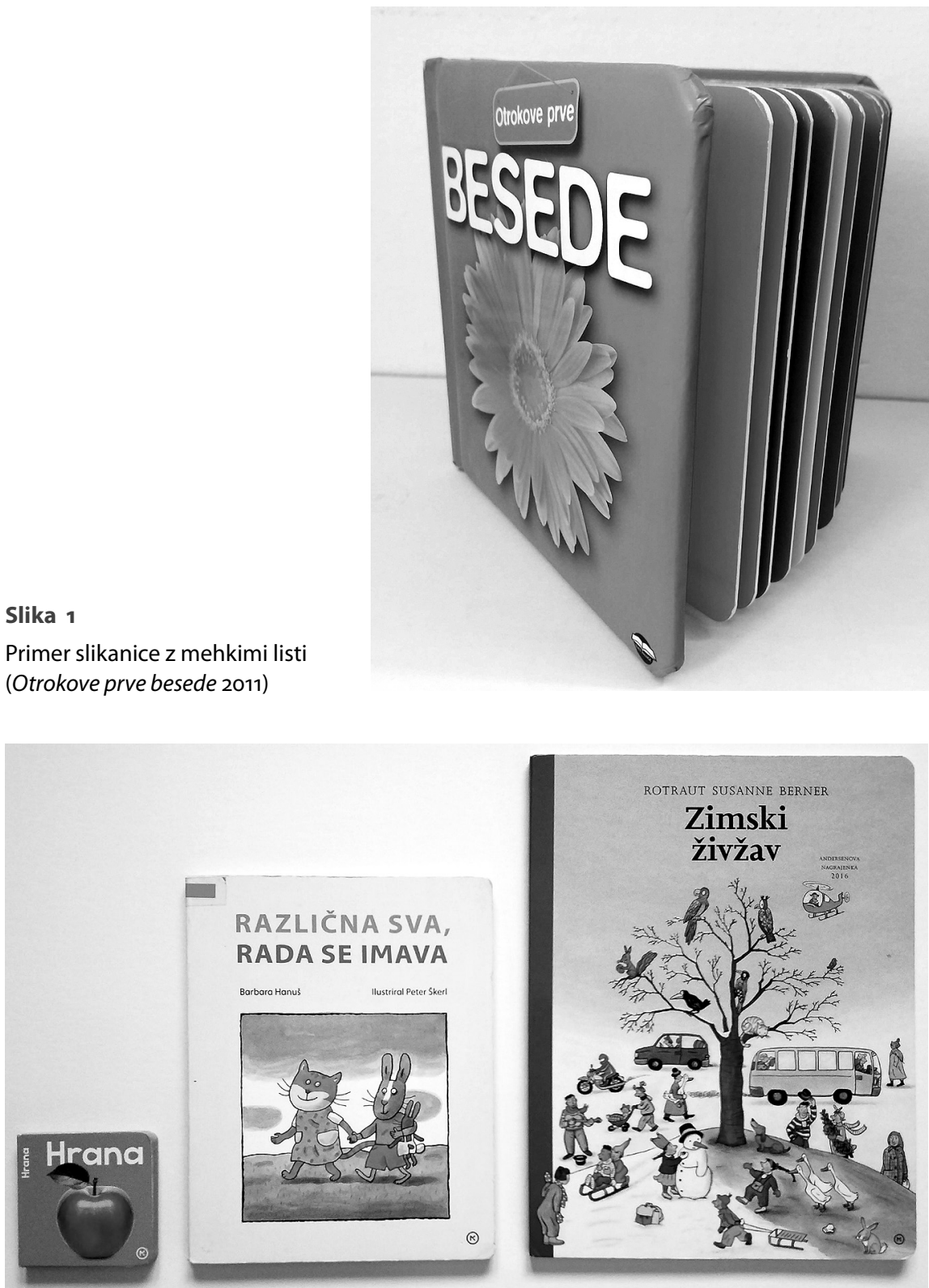

Slika 2 Različne velikosti slikanic (Hrana 2018; Hanuš 2013; Berner 2016)

Pogosta oblika slikanice je tudi leporelo ali zgibanka (slika 4). Marjana Kobe je v monografiji Pogledi na mladinsko književnost (1987, 30-33) povezovala 


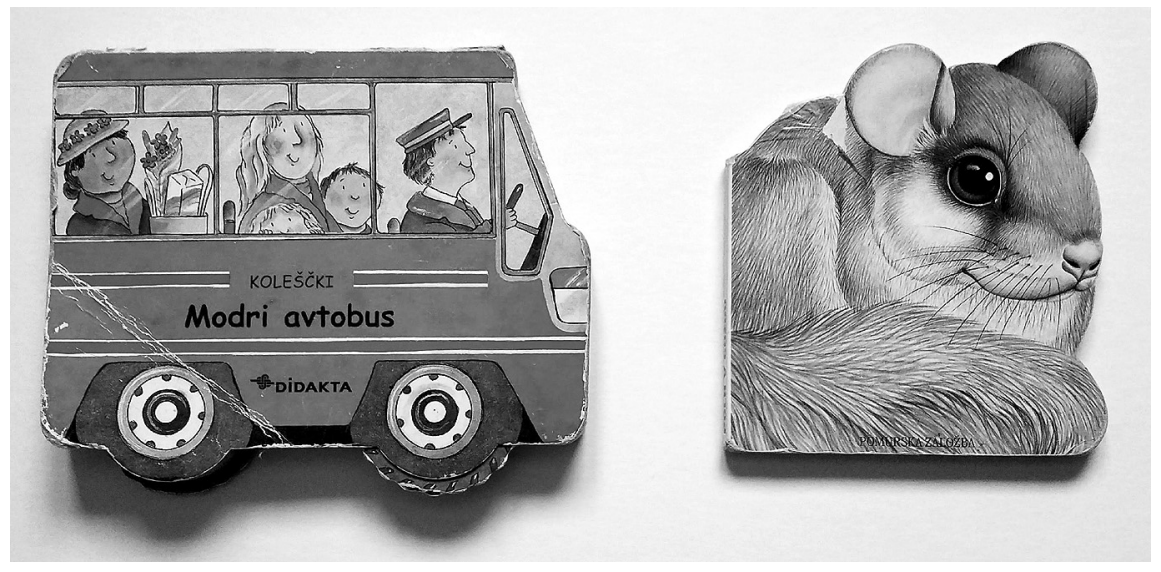

Slika 3 Različne oblike slikanic (Oliver 2010; Rizzatti 1993)

Slika 4

Primer leporela (Grafenauer 2018)

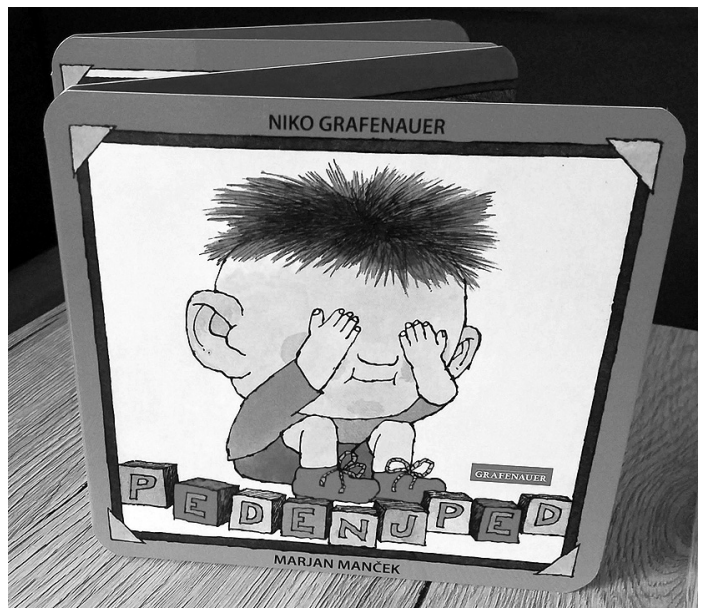

obliko slikanice s starostjo bralca, kar je bilo na podlagi do takrat izdanega gradiva utemeljeno. Teoretičarka je delila slikanice $v$ tri zahtevnostne stopnje: v prvo zahtevnostno stopnjo je uvrščala leporelo ali zložljivo kartonsko zgibanko, ki (Kobe 1987, 30) »še nima oblike knjige. [...] Namenjena je otrokom do 2., 3. leta, zato je po zunanji obliki še nekakšna prehodna stopnja med igračo in 'pravo' knjigo, po vsebini pa doživljajsko najpreprostejša. « Ta oblika slikanice je bila v preteklosti obravnavana kot slikanica za dojenčke, vendar je treba poudariti, da v zadnjem desetletju nastajajo tudi leporela, ki so naslovniško odprta (Peklar 2005), zato oblike knjige ne moremo (več) enačiti s starostno skupino najmlajših bralcev, čeprav še vedno prevladuje $v$ prvem 


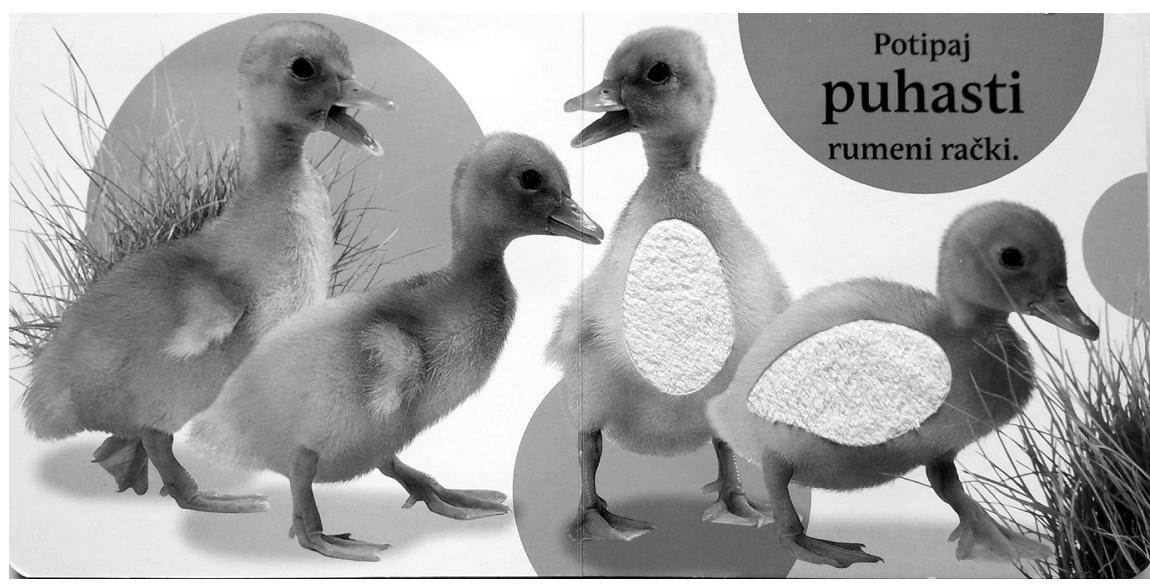

Slika 5 Primer slikanice potipanke (Živalski mladički 2014)

starostnem obdobju. Leporelo lahko ima besedilo (običajno posamezna beseda, največ do dve vrstici) ali pa gre za tip slikanice brez besedila.

Slikanice se razlikujejo tudi po stopnji interaktivnosti: opazujemo lahko, kako z različnimi elementi spodbujajo otroka k rokovanju s knjigo. Pogosto lahko zasledimo t. i. potipanke. Na posameznih straneh slikanice so prisotni različni materiali, ki otroka spodbudijo, da jih potipa in občuti določene lastnosti (gladko, hrapavo, mehko, trdo itd.) Problem, ki se pri tem pojavi, je vstavljanje različnih materialov v informativne slikanice.

Na sliki 5 lahko opazujemo kolaž podob - štiri račje mladiče, modre kroge na belem ozadju in travo. Trup dveh mladičev je oblikovan tako, da je v podobo vstavljeno blago (na otip spominja na brisačo). V vstavljenem besedilu je navodilo »Potipaj puhasti rumeni rački.« Informacija, ki jo dobi otrok, je povsem napačna, saj puh račjih mladičev na otip ni enak kot površina vstavljenega blaga. Glede na to, da je delež informativnih slikanic mnogo manjši od deleža leposlovnih slikanic (Ganea, Ma in DeLoache 2011), je zelo težko izbrati kakovostno informativno slikanico. Hkrati pa raziskave kažejo, da lahko štiriletni otroci informacije v slikanicah s področja naravoslovja prenesejo $v$ pojasnjevanje življenjskih situacij, npr. spoznavanje živali (Ganea, Ma in DeLoache 2011).

$V$ to skupino lahko uvrstimo tudi zvočne slikanice in slikanice s premičnimi elementi. Zvočne slikanice so največkrat oblikovane tako, da otrok pritisne na sličico in s tem aktivira zvok: oglašanje živali, prevozna sredstva ipd. (slika 6).

V originalu ima slikanica Kajetana Koviča Maček Muri (1975) približno 10 strani besedila ( $v$ to je všteto tudi 6 pesmi). Po obsegu torej Maček Muri pre- 


\section{Slika 6}

Primer zvočne knjige (Kovič 2014)

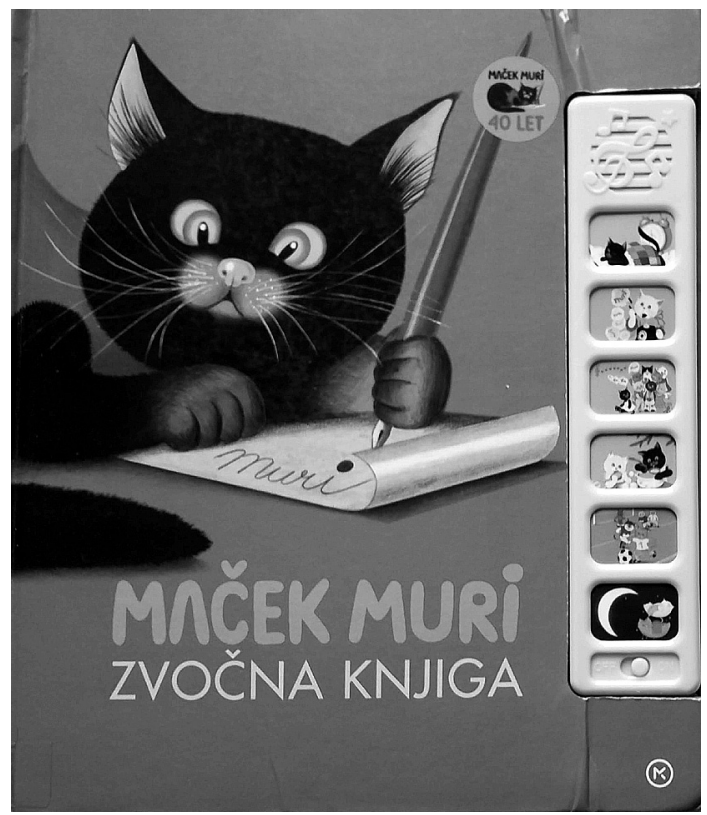

sega 1. otrokovo starostno obdobje, je pa res, da je Muri sam po sebi blagovna znamka. ${ }^{3}$ Zvočna knjiga vsebuje le po nekaj vrstic posamezne pesmi iz izhodiščne slikanice, je brez proznega besedila.

K aktivnosti otroke spodbujajo tudi knjige s premičnimi elementi: (1) »popup« knjige (ob odpiranju strani se v prostor dvigujejo tridimenzionalne oblike, (2) knjige z vrtljivimi elementi: $z$ vrtenjem posameznih elementov v slikanici se odkrivajo nove podobe, (3) knjige v obliki kukala, (4) knjige z zavihki: ta oblika knjig ima delčke, ki jih mora bralec dvigniti, da bi videl, kaj se skriva pod njimi (slika 7 zgoraj in spodaj), (5) knjige $z$ okenci »povleci in poglej« - po namenu enake slikanicam z zavihki, saj prav tako spodbujajo otrokovo aktivnost in radovednost. Začetnik slikanic s premičnimi elementi je Eric Hill, ki je leta 1980 izdal prvo knjigo o Pikiju, v slovenščini Kje je Piki? (Hill 1990). ${ }^{4}$

${ }^{3}$ Literarni lik mačka Murija srečamo tudi kot plišasto lutko, igralne kocke, posteljnino, mehko knjigo iz blaga, miniaturko, lonček, interaktivno multimedijsko knjigo ipd. Blagovno znamko je Mladinska knjiga ustvarila tudi s slikanico Ele Peroci Muca Copatarica (1957), ki je trenutno slikanica z drugo najvišjo naklado na Slovenskem (173.00o izvodov), Maček Muri (Kovič 1975) je na tretjem mestu (171.00o izvodov); na prvem mestu je naslovniško odprta slikanica Martin Krpan (1954) Frana Levstika (več kot 250.000 izvodov). Za podatke o številu izdaj se zahvaljujemo urednici pri Mladinski knjigi Ireni Matko Lukan.

${ }^{4}$ Eric Hill (1927-2014) je s serijo o Pikiju doživel nesluten uspeh: prevedena je v več kot 60 jezikov, 


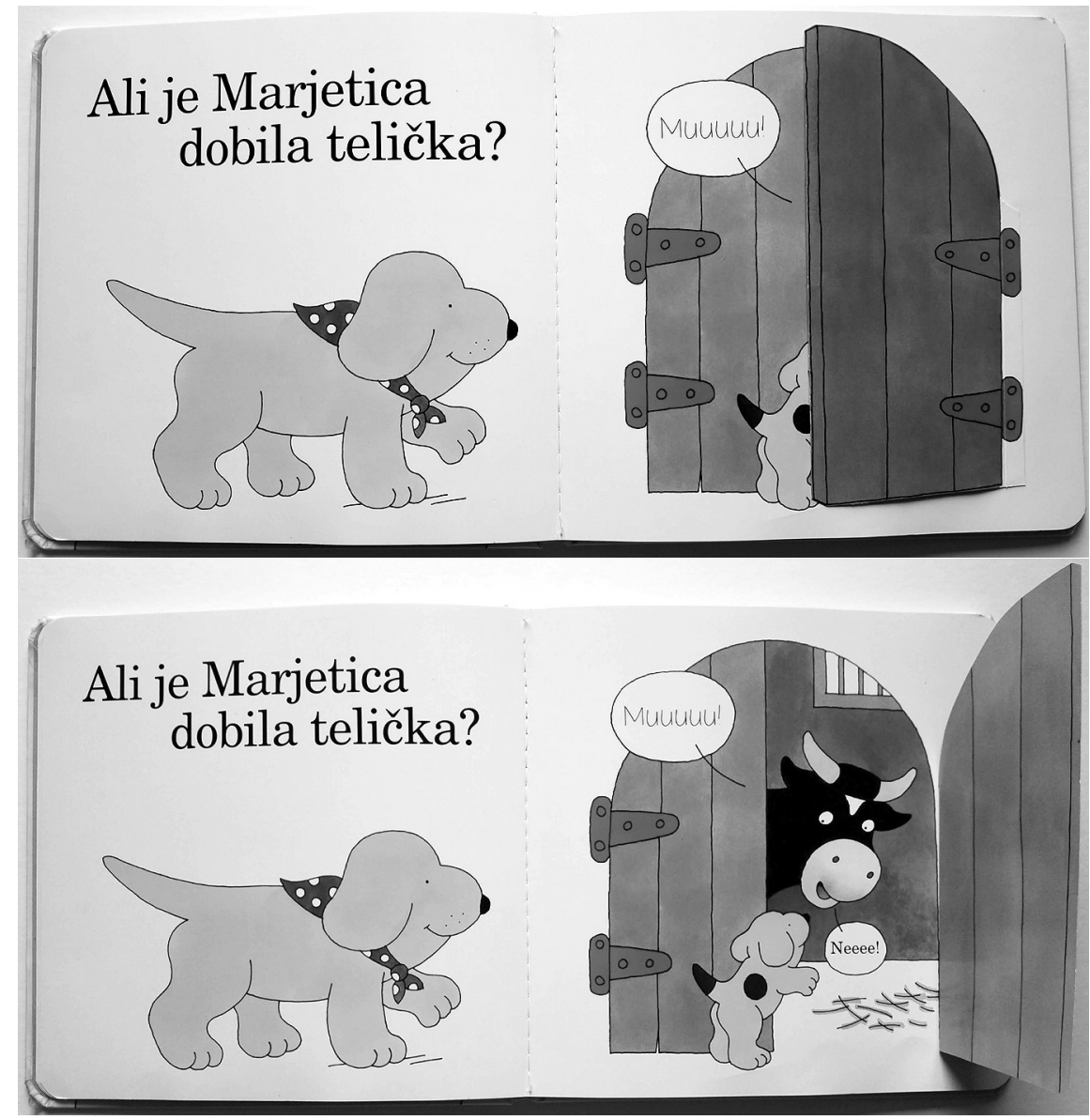

Slika 7 Primer knjige z zavihki (Hill 2014)

\section{Vsebinske posebnosti slikanic za najmlajše otroke}

Slikanice, ki so namenjene otrokom v prvem starostnem obdobju, se razlikujejo po količini besedila in ilustracij. Za najmlajše otroke so pogoste slikanice brez besedila ali z eno besedo na stran (fotografija ali ilustracija predmeta in njegovo poimenovanje). Sledijo slikanice $s$ krajšim besedilom, ki je običajno zasnovano kot naloga, usmerjajoča otrokovo pozornost. Tak primer je slikanica z naslovom Muca pa nagaja Slavice Remškar (2015), ki je sestavljena iz enajstih parov ilustracij (slika 8).

v nakladi več kot 60 milijonov knjig; za uspeh je gotovo zaslužna tudi produkcija animiranih filmov. 


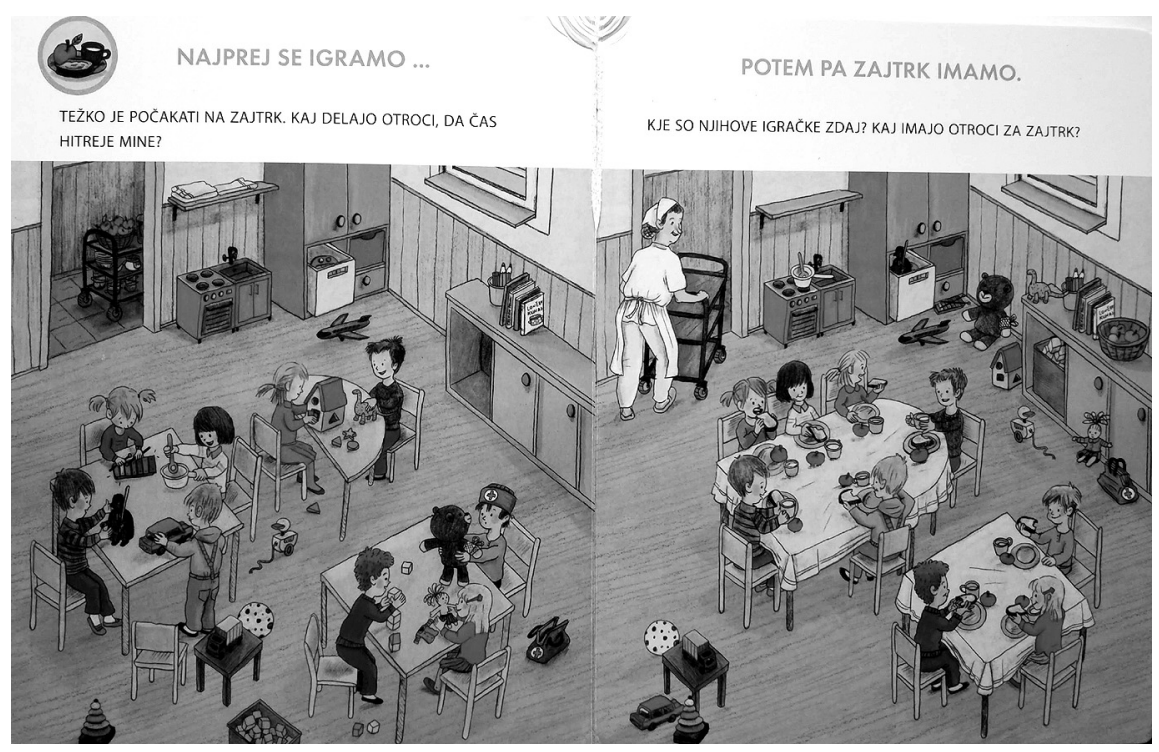

Slika 8 Primer slikanice z nalogo (Remškar 2015)

Pari ilustracij so zasnovani tako, da je upodobljeno stanje prej in potem. Pripadajoče besedilo na levi strani opiše stanje, npr. »Nobenega otroka ni več v vrtcu. Nobene vzgojiteljice. Niti snažilke. V igralnico pa je prišla mala vila!« (Remškar 2015), ali pa postavi vprašanje, npr. »Težko je počakati na zajtrk. Kaj delajo otroci, da čas hitreje mine?« (Remškar 2015). Ilustracije na desni strani pa so večinoma dopolnjene $z$ vprašanji, ki otroka usmerijo $v$ iskanje razlik med levo in desno stranjo $v$ slikanici.

Naslednji primer slikanice, ki otroka usmerja v aktivno sodelovanje, je slikanica z naslovom Medvedek, kaj delaš? Slavice Remškar (2014). Slikanica je sestavljena iz šestih zgodb, ki prikazujejo medvedka pri različnih dejavnostih. Interakcija med besedilom in ilustracijo je izrazito dopolnjujoča, saj pomena ne moremo razbrati, če med branjem besedila ne opazujemo ilustracij. Posamezna zgodba je dolga tri ali štiri strani. Na vsaki strani so štiri ali tri manjše ilustracije. Slikanica je zasnovana tako, da je skoraj pod vsako ilustracijo pripadajoče besedilo oz. vprašanje, ki spodbuja otrokovo opazovanje (slika 9).

V slikanici Barbare Hanuš Različna sva, rada se imava (2013) sta oblika in postavitev besedila takšni, da otroku v predbralnem obdobju omogočata sodelovanje pri branju besedila. Slikanica je zasnovana tako, da je v zgornjem delu strani postavljena ilustracija, pod njo je umeščeno besedilo. Besedilo vključuje manjši ilustraciji - glavo mačke in zajca -, na vsaki strani ti dve ilustraciji 


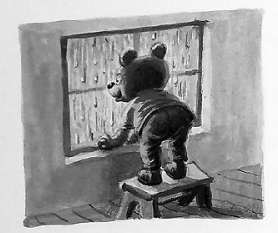

O, DEŽUJE!

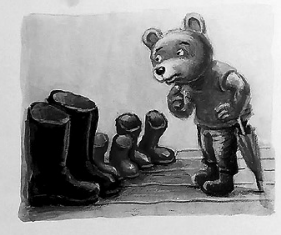

KATERI SKORNUI

SO MEDVEDKOVI?

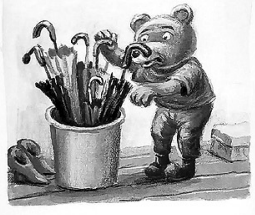

KJE JE MEDVEDKOV DEŻNIK?

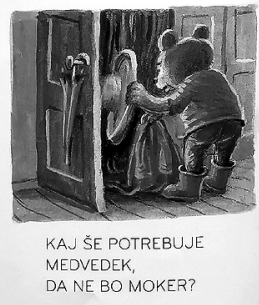

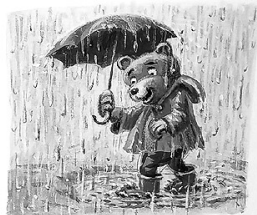

BODO NOGE MOKRE? NE MEDVEDEK IMA ŚKORNJE.

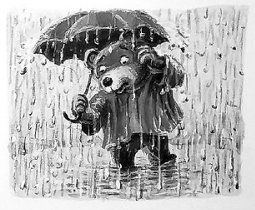

JOJ, NOGE SO MOKRE. ZAKAJ?

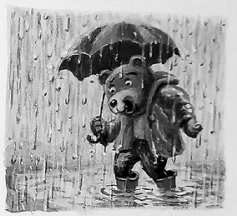

BODO NOGE MOKRE? HEJ VODE JE ZELO VELIKO

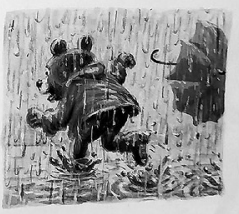

BO MEDVEDEK MOKER? MALO ŽE

Slika 9 Primer slikanice, ki otroka usmerja v aktivno sodelovanje (Remškar 2014)

opozarjata na dialog med literarnima likoma; gre torej za dramsko delo, saj slikanica vsebuje dialoge brez veznega besedila ali didaskalij. Besedilo je napisano v črni barvi, v vsaki povedi pa se pojavi beseda, ki je natisnjena v drugi barvi (npr. zajec pove, da hodi pod rumenim dežnikom; beseda dežnik je zapisana v rumeni barvi). Barva izpostavljene besede se likovno navezuje na zgornjo ilustracijo (slika 10). Ob koncu slikanice so dodane naloge, primerne za otroke v prvem starostnem obdobju.

K vsebinskim posebnostim slikanic za otroke v prvem starostnem obdobju lahko umestimo tudi odnos med besedilom in ilustracijo. Praviloma se informacija, ki je podana $v$ besedilu, ponovi v ilustraciji, zato govorimo o simetrični interakciji (Nikolajeva 2003) (slika 11). Tako lahko vidimo npr. fotografijo predmeta in poimenovanje (npr. beseda avto in fotografija avtomobila). Kljub temu je potrebno otroke usmerjati v opazovanje slikovnega dela (npr. spodbudimo otroka, da pokaže, kje ima avtomobil kolesa, brisalce ..., pove, kakšne barve je avto ipd.). Pri kompleksnejših ilustracijah v slikanicah, ki so primerne za prvo starostno obdobje, lahko $z$ otroki raziskujemo razpoloženje, čustvena stanja ipd. Dober primer simetrične interakcije je zbirka slikanic Gaje Kos o grdavših (2010; 2016; 2018).

Slikopisi so posebna oblika slikanic, ki imajo dopolnjevalno interakcijo: del pomena zgodbe izvemo iz besedila, $v$ vsaki povedi pa so posamezne besede 


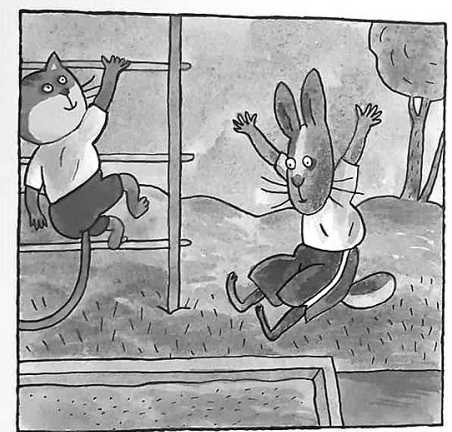

RAD SKAČEM

JAZ PA RADA PLEZAM.

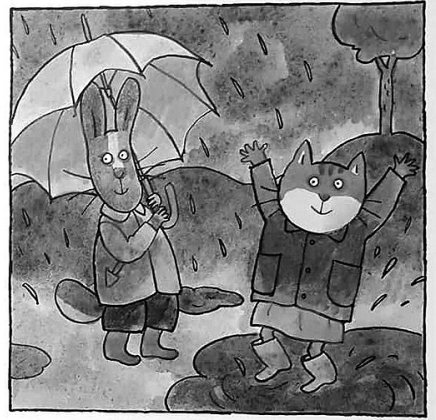

RADA HODIM PO LUŽAH.

KO DEŽUJE, SE SKRIJEM POD DEŽNIK.

Slika 10 Primer dialoga v slikanici (Hanuš 2013)

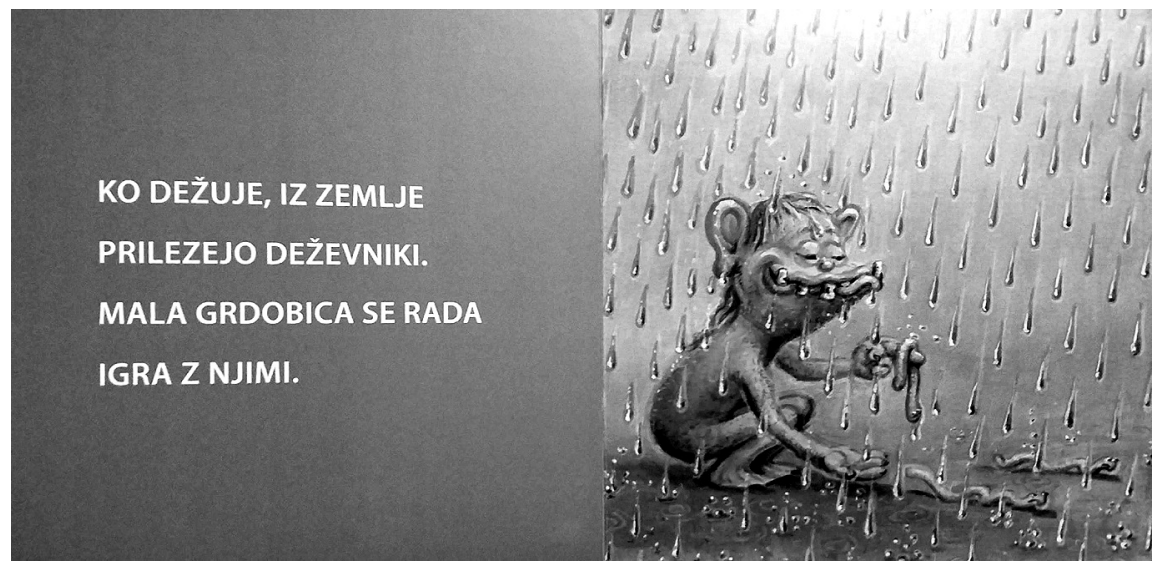

Slika 11 Primer simetrične interakcije (Kos 2016)

nadomeščene s sličicami, torej del zgodbe izvemo samo skozi ilustracije. Te nadomeščajo večinoma samostalnike, redkeje tudi glagole. Večinoma so slikopisi dobra spodbuda pri začetnem opismenjevanju, so pa tudi preizkušena bralna spodbuda za mlajše otroke. Sličice morajo biti takšne, da otrok nemudoma ugotovi, katere besede nadomeščajo sličice ( $v$ slabem slikopisu bralec ni povsem prepričan, ali je povedal pravo besedo za sličico). Veliko slikopisov za najmlajše ustvarjajo npr. Urša Krempl in ilustratorka Urška Stropnik Šonc 
kot stalni ustvarjalni tim (Krempl 2003; 2009a; 2009b), Cvetka Sokolov z različnimi ilustratorkami, npr. z Ano Zavadlav (Sokolov 2012) ali Tanjo Komadina (Sokolov 2014), ter Slavica Remškar z Bojano Dimitrovski (2013).

Proti koncu prvega starostnega obdobja otrokom ponudimo kakovostne leposlovne slikanice s trdimi platnicami in tankimi (navadnimi) vložnimi listi; paziti je treba, da besedila niso predolga in da motivno-tematsko ustrezajo tej starosti. Podajamo nekaj primerov kakovostnih izvirnih slovenskih slikanic, ki so bile preizkušene tudi z otroki tega starostnega obdobja. ${ }^{5}$

\section{Sklep}

Leposlovne in informativne slikanice, ki so primerne za prvo starostno obdobje, imajo enake zakonitosti kot vsa kakovostna literatura: spoznavna, etična in estetska plast morajo biti $v$ besedilu, ilustraciji in $v$ njuni interakciji (oz. vsebinsko-oblikovnem odnosu) odlične. Z vsebinskega stališča morajo biti izbrana takšna besedila, ki jih otrok zmore razumeti (paziti je potrebno na dolžino besedila, na število različnih besed, ki se v nekem besedilu pojavljajo, na temo in motive, ki so otroku blizu), zanemarljiva pa ni niti oblikovna podoba (materiali, velikost, oblika slikanic ipd.).

Leposlovne slikanice za dojenčke in malčke morajo biti skrbno izbrane, namenjene morajo biti njihovim kognitivnim zmožnostim. Različne skrajšave, ki jih najdemo na tržišču, so večinoma zgrešene, saj gre za prirejanje besedil, namenjenih bistveno starejšim otrokom. Ali, kakor opozarjajo v smernicah za otroške knjižnice, namenjene populaciji od o-18 let (International Federation of Library Associations 2018, 13): „Otroci niso homogena ciljna skupina. Njihove različne sposobnosti, nadarjenosti, talenti in potrebe se razlikujejo glede na njihovo starost, kulturno, sociološko in ekonomsko ozadje.« V prvem starostnem obdobju, ko se otrok šele uči besedišča in osnovnih konceptov razumevanja sveta, ne more razumeti besedil - četudi zelo skrajša-

\footnotetext{
${ }^{5}$ Npr. Pojte, pojte, drobne ptice, preženite vse meglice (2017), Pleši, pleši, črni kos! (2017), Biba buba baja (Voglar 2019), Živalske uspavanke (Prap 2018), Male živali (Prap 2006), Mojočka (Prap 2007), Kuža Pazi (Bitenc 2007), Lestev in sirček (Košuta 2001), Lončekna pike (Štefan 2019), Škratjev sadovnjaku (Gregorič Gorenc 2017č), Škratje na vrtu (Gregorič Gorenc 2017b), Škratje v gozdu (Gregorič Gorenc 2017c), Škratje na kmetiji (Gregorič Gorenc 2017a), Muca Copatarica (Peroci 1957), Plašček za Barbaro (Zupan 1974), Mali medo (Kovač 2019), Kako sta Bibi in Gusti preganjala žalost (Mlakar 2004), Kako sta Bibi in Gusti porahljala prepir (Mlakar 2006), Kako sta Bibi in Gusti sipala srečo (Mlakar 2010), Velika žehta (Möderndorfer 2011), Petelinček (Radovanovič 2014), Iščemo hišico (Štefan 2019), Žiga špaget gre v širni svet (Kermauner 2010), Žiga špaget je za punce magnet (Kermauner 2017), Sovica Oka (Makarovič 2017), O mrožku, ki si ni hotel striči nohtov (Svetina 1999), Mrožek dobi očala (Svetina 2003), Ringaraja (Svetina 2009), Medved in Miška 1 (Koren 2010), Medved in Miška 2 (Koren 2013).
} 
nih -, ki presegajo njegovo izkušnjo. Dober primer so npr. dela Davida McKeeja (1998a; 1998b; 1998c; 1998č) o slončku Elmerju, pri čemer ne gre za skrajšave, temveč za postopnost: otrokom v prvem starostnem obdobju so namenjene kartonke o Elmerjevih barvah, prijateljih ...v drugem starostnem obdobju pa preide na poslušanje izhodiščne slikanice o vključujočih odnosih. Kakovostne informativne slikanice se odlikujejo po slikovnem gradivu, ki nazorno prikazuje nek predmet (fotografijo ali realistično upodobitev nekega predmeta ali pojava). Kakovostne slikanice za otroke prvega starostnega obdobja so, ob nesporni jezikovni in likovni podobi, zasnovane tako, da na besedilni in oblikovni ravni otroka spodbujajo k aktivnemu sodelovanju, torej k poslušanju, natančnemu opazovanju ilustracij, sledenju natisnjenemu besedilu, iskanju informacij $v$ besedilu in sliki ter podajanju odgovorov na vprašanja.

\section{Zahvala}

Avtorici sta prispevek napisali v okviru projekta OBJEM - Bralna pismenost in razvoj slovenščine (Ozaveščanje, Branje, Jezik, Evalvacija, Modeli), šifra projekta OP20.01462, vodja dr. Sandra Mršnik, ki ga vodi Zavod RS za šolstvo; naložbo sofinancirata Republika Slovenija in Evropska unija iz Evropskega socialnega sklada.

Za dovoljenje za objavo ilustrativnega gradiva se avtorici zahvaljujeta založbam Mladinska Knjiga, Grafenauer in Miš.

\section{Literatura}

Bates, E., in J. C. Goodman. 2001. »On the Inseparability of Grammar and the Lexicon: Evidence from Acquisition. "V Essential Readings in Developmental Psychology: Language Development; The Essential Readings, ur. M. Tomasello in E. Bates, 134-162. Malden: Blackwell.

Berner, R. S. 2016. Zimski živžav. Ljubljana: Mladinska knjiga.

Bitenc, J. 2007. Kuža Pazi. Ilustrirala D. Simčič. Ljubljana: Erimas.

Carl, E., 1997. Zelo lačna gosenica. Ljubljana: Epta.

Dwyer, J., in B. S. Neuman. 2008. »Selecting Books for Children Birth Through Four: A Developmental Approach.« Early Childhood Education Journal 35 (6): 489-494.

Ganea, A. P., M. Bloom Picard in J. S. DeLoache. 2008. »Transfer between Picture Books and the Real World by Very Young Children." Journal of Cognition and Development 9 (1): 46-66.

Ganea, A. P., P. Ma in J. S. DeLoache, J. S., 2011. "Young Children's Learning and Transfer of Biological Information from Picture Books to Real Animals." Child Development 82 (5): 1421-1433.

Grafenauer, N. 2018. Pedenjped. Ilustriral M. Manček. Ljubljana: Grafenauer. 
Gregorič Gorenc, B. 2017a. Škratje na kmetiji. Ilustrirala A. Gregorič. Murska Sobota: Ajda.

- 2017b. Škratje na vrtu. Ilustrirala A. Gregorič. Murska Sobota: Ajda.

—. 2017c. Škratje v gozdu. Ilustrirala A. Gregorič. Murska Sobota: Ajda.

_. 2017č. Škratje v sadovnjaku. Ilustrirala A. Gregorič. Murska Sobota: Ajda.

Hanuš, B. 2013. Različna sva, rada se imava. Ilustriral P. Škerl. Ljubljana: Mladinska knjiga.

Haramija, D., in J. Batič. 2013. Poetika slikanice. Murska Sobota: Franc-Franc.

Hill, E. 1990. Kje je Piki? Ljubljana: Mladinska knjiga.

- 2014. Piki obišče kmetijo. Ljubljana: Mladinska knjiga.

Hrana. 2018. Ljubljana: Mladinska knjiga.

International Federation of Library Associations. 2018. IFLA Guidelines for Library Services to Children aged o-18. Ur. Carolynn Rankin. Haag: International Federation of Library Associations.

Kermauner, A. 2010. Žiga špaget gre v širni svet. Ilustriral Z. Čoh. Dob: Miš.

—. 2017. Žiga špaget je za punce magnet. Ilustriral Z. Čoh. Ljubljana: Zveza društev gluhih in naglušnih Slovenije.

Kobe, M. 1987. Pogledi na mladinsko književnost. Ljubljana: Mladinska knjiga.

Koren, M. 2010. Medved in Miška 1. Ilustriral B. Jurc. Čedad: Zadruga Novi Matajur.

- 2013. Medved in Miška 2. Ilustriral B. Jurc. Čedad: Zadruga Novi Matajur. Kos, G. 2010. Grdavši. Ilustriral Z. Čoh. Dob pri Domžalah: Miš.

. 2016. Grdavši in dež. Ilustriral Z. Čoh. Dob pri Domžalah: Miš. . 2018. Grdavši in presenečenje. Ilustriral Z. Čoh. Dob pri Domžalah: Miš.

Košuta, M. 2001. Lestev in sirček. Ilustrirala M. Kozjek. Ljubljana: Mladinska knjiga.

Kovač, P. 2019. Mali medo. Ilustrirala J. Reichman. Ljubljana: Mladinska knjiga.

Kovič, K. 1975. Maček Muri. Ilustrirala J. Reichman. Ljubljana: Mladinska knjiga.

—. 2014. Maček Muri. Ilustrirala J. Reichman. Zvočna knjiga. Ljubljana: Mladinska knjiga.

Krempl, U. 2003. Zgodbe v sličicah. Ilustrirala U. Stropnik Šonc. Domžale: Studio Hieroglif.

- 2009. Pravi prijatelj. Ilustrirala U. Stropnik Šonc. Mengeš: Izolit.

- 2009. Zajčkove počitnice. Ilustrirala U. Stropnik Šonc. Mengeš: Izolit.

Krolak, L., 2005. The Role of Libraries in the Creation of Literate Environments. Hamburg: UNESCO.

Levstik, F. 1954. Martin Krpan. Ilustriral T. Kralj. Ljubljana: Mladinska knjiga.

Lysaker, J., in E. Hopper. 2015. »A Kindergartner's Emergent Strategy Use during Wordless Picture Book Reading.« The Reading Teacher 68 (8): 649-657.

Makarovič, S. 2017. Sovica Oka. Ilusdtriral G. Vahen. Ljubljana: Mladinska knjiga. Marjanovič Umek, L. 2007. »Vloga otroškega govora v razvoju zgodnje in kasnejše pismenosti.«V Stopenjskost pri usvajanju pismenosti: postopen pouk 
bralne pismenosti na vseh ravneh šolanja, ur. J. Vintar, 36-47. Ljubljana: Zavod Republike Slovenije za šolstvo.

McKee, D. 1998a. Elmerjeve barve. Ljubljana: Korotan.

—. 1998b. Elmerjev dan. Ljubljana: Korotan.

-1998c. Elmerjevi prijatelji. Ljubljana: Korotan.

-1998č. Elmerjevo vreme. Ljubljana: Korotan.

Mlakar, I. 2004. Kako sta Bibi in Gusti preganjala žalost. Ilustrirala K. Krhin. Radovljica: Didakta.

_. 2006. Kako sta Bibi in Gusti porahljala prepir. Ilustrirala K. Krhin. Radovljica: Didakta.

- 2010. Kako sta Bibi in Gusti sipala srečo. Ilustrirala K. Krhin. Radovljica: Didakta.

Möderndorfer, V. 2011. Velika žehta. Ilustrirala T. Komadina. Ljubljana: Mladinska knjiga.

Nikolajeva, M. 2003. »Verbalno in vizualno: slikanica kot medij." Otrok in knjiga 30 (58): 5-26.

Oliver, J. 2010. Modri avtobus. Radovljica: Didakta.

Otrokove prve besede. 2011. Ljubljana: Mladinska knjiga.

Pečjak, S. 1995. Ravni razumevanja in strategija branja. Trzin: Different.

Peklar, A. 2005. Fant z rdečo kapico. Ljubljana: Inštitut za likovno umetnost.

Peroci, E. 1957. Muca copatarica. Ilustrirala A. Gošnik Godec. Ljubljana: Mladinska knjiga.

Pleši, pleši, črni kos! 2017. Ilustrirala M. Stupica. Ljubljana: Mladinska knjiga.

Pojte, pojte, drobne ptice, preženite vse meglice. 2017. Ilustrirala M. Stupica. Ljubljana: Mladinska knjiga.

Projekt OBJEM. 2018. »Gradniki bralne pismenosti.« Delovno gradivo, Zavod Republike Slovenije za šolstvo, Ljubljana.

Piasta, S. B., L. M. Justice, A. S. McGinty in J. N. Kaderavek. 2012. »Increasing Young Children's Contact With Print During Shared Reading: Longitudinal Effects on Literacy Achievement."Child Development 83 (3): 810-820.

Peroci, E. 1957. Muca copatarica. Ilustrirala A. Gošnik Godec. Ljubljana: Mladinska knjiga.

Prap, L. 2006. Male živali. Ljubljana: Mladinska knjiga.

- 2007. Moj očka. Ljubljana: Mladinska knjiga.

_. 2017. Živalske uspavanke. Ljubljana: Mladinska knjiga.

Priporočilo sveta o ključnih kompetencah za vseživljenjsko učenje. 2018. Uradni list Evropske unije $\mathrm{C} 189$.

Radovanovič, V. 2014. Petelinček. Ilustrirala K. Krhin. Murska Sobota: Ajda.

Remškar, S. 2013. Leto, leto pisano. Ilustrirala B. Dimitrovski. Ljubljana: Mladinska knjiga.

_. 2014. Medvedek kaj delaš? Ilustriral Z. Čoh. Ljubljana: Mladinska knjiga. 
. 2015. Muca pa nagaja. Ilustrirala T. Komadina. Ljubljana: Mladinska knjiga.

Rizzatti, L. 1993. Polh v gozdu. Murska Sobota: Pomurska založba.

Snow, C., in A. Ninio. 1986. »The Contracts of Literacy: What Children Learn from Learning to Read Books." V Emergent Literacy: Writing and Reading, ur. W. Teale in E. Sulzby, 116-138. Norwood, NJ: Ablex.

Sokolov, C. 2014. In kaj boš po poklicu ti? Ilustrirala T. Komadina. Ljubljana: Mladinska knjiga.

. 2012. V našem vrtcu. Ilustrirala A. Zavadlav. Ljubljana: Mladinska knjiga. Svetina, P. 1999. O mrožku, ki si ni hotel striči nohtov. Ilustrirala M. Osojnik. Ljubljana: Mladinska knjiga.

—. 2003. Mrožek dobi očala. Ilustrirala M. Osojnik. Ljubljana: Mladinska knjiga.

- 2009. Ringaraja. Ilustriral M. Manček. Ljubljana: Mladinska knjiga.

Štefan, A. 2016. Iščemo hišico. Ilustrirala A. Gošnik Godec. Ljubljana: Mladinska knjiga.

-2019. Lončekna pike. Ilustrirala J. Reichman. Ljubljana: Mladinska knjiga. Voglar, M. 2019. Biba buba baja. Ilustrirala L. Osterc. Ljubljana: Mladinska knjiga. Zupan, V. 1974. Plašček za Barbaro. Ilustrirala M. L. Stupica. Ljubljana: Mladinska knjiga.

Živalski mladički. 2014 Ljubljana: Mladinska knjiga.

\section{Picture Books in Early Childhood}

This paper focuses on reading picture books to children in early childhood. Literacy development is a lifelong process which adults pass to children and are responsible for. During the child's first year, the focus is on the development of family reading, as children are read by the adults within their family (nonprofessional reading intermediaries). However, when a child starts the kindergarten, he or she is faced with targeted learning activities related to literacy. Early childhood picture books are introduced according to their special design features: materials used, book size (child appropriate), form (lift-the-flap books, books with rotating elements, pop-up books, etc.), picture books using sound effects, puppets, etc. Content-related restrictions of literary and informative picture books are introduced in respect of children's integrated development. Keywords: literacy, picture books, informative picture books, literary picture books, early childhood 